\title{
European guidelines for quality assurance in colorectal cancer screening and diagnosis. First Edition Annotations of colorectal lesions
}

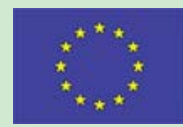

Co-Funded by

the Health Programme of the European Union

Authors

Institutions
M. Vieth ${ }^{1}$, P. Quirke², R. Lambert ${ }^{3}$, L. von Karsa ${ }^{4}$, M. Risio ${ }^{5}$

Institutions are listed at the end of article.
Keywords

- mass screening

- colorectal neoplasms

- histopathology

- classification

- serrated lesions

- multidisciplinary evidence-based guidelines

- population-based programmes
Bibliography

Dol http://dx.doi.org/ 10.1055/s-0032-1309798 Endoscopy 2012; 44:

SE131-SE139

(C) Georg Thieme Verlag KG Stuttgart · New York

ISSN 0013-726X

\section{Corresponding author}

\section{Vieth}

Institute of Pathology

Klinikum Bayreuth GmbH

Preuschwitzerstr. 101

95445 Bayreuth

Germany

vieth.lkpathol@uni-bayreuth.de qas@iarc.fr
Multidisciplinary, evidence-based guidelines for quality assurance in colorectal cancer screening and diagnosis have been developed by experts in a project coordinated by the International Agency for Research on Cancer. The full guideline document covers the entire process of populationbased screening. It consists of 10 chapters and over 250 recommendations, graded according to the strength of the recommendation and the supporting evidence. The 450-page guidelines and

\section{Background \\ $\nabla$}

According to the most recent estimates by the International Agency for Research on Cancer [10] colorectal cancer (CRC) is the most common cancer in Europe with 432000 new cases in men and women reported annually. It is the second most common cause of cancer deaths in Europe with 212000 deaths reported in 2008. Worldwide CRC ranks third in incidence and fourth in mortality with an estimated 1.2 million cases and 0.6 million deaths annually. The European Union (EU) recommends population-based screening for breast, cervical and colorectal cancer using evidence-based tests with quality assurance of the entire screening process including diagnosis and management of patients with screen-detected lesions [7]. The EU policy takes into account the principles of cancer screening developed by the World Health Organization [83] and the extensive experience in the EU in piloting and implementing population-based cancer screening programmes [75]. Screening is an important tool in cancer control in countries with a significant burden of CRC, provided the screening services are high quality [76]. The presently reported multidisciplinary, evidence-based guidelines for quality assurance in colorectal cancer screening and diagnosis have been developed by experts and published by the EU [59]. the extensive evidence base have been published by the European Commission. The chapter on quality assurance in pathology was supplemented by an annex describing in greater detail some issues raised in the chapter, particularly details of special interest to pathologists. The content of the annex is presented here to promote international discussion and collaboration by making the issues discussed in the guidelines known to a wider professional and scientific community.

\section{Methods}

The methods used are described in detail elsewhere in this supplement [34]. Briefly, a multidisciplinary group of authors and editors experienced in programme implementation and quality assurance in colorectal cancer screening and in guideline development collaborated with a literature group consisting of epidemiologists with special expertise in the field of CRC and in performing systematic literature reviews. The literature group systematically retrieved, evaluated and synthesized relevant publications according to defined clinical questions (modified PatientIntervention-Comparison-Outcome-Study method). Bibliographic searches for most clinical questions were limited to the years 2000 to 2008 and were performed on Medline, and in many cases also on Embase and The Cochrane Library. Additional searches were conducted without date restrictions or starting before 2000 if the authors or editors who were experts in the field knew that there were relevant articles published before 2000. Articles of adequate quality recommended by authors because of their clinical relevance were also included.

Only scientific publications in English, Italian, French and Spanish were included. Priority was given to recently published, systematic reviews or clinical guidelines. If systematic reviews of high methodological quality were retrieved, the 
Table 7A.1 Grading of gastrointestinal neoplasia

\begin{tabular}{|lllll} 
& Normal & $\begin{array}{l}\text { Low-grade mucosal/ } \\
\text { intraepithelial neoplasia } \\
\text { (LGMN) }\end{array}$ & $\begin{array}{l}\text { High-grade mucosal/ } \\
\text { intraepithelial neoplasia } \\
\text { (HGMN) }\end{array}$ & $\begin{array}{l}\text { Invasive } \\
\text { Cancer }\end{array}$ \\
\hline Glands & non-branching & villous & $\begin{array}{l}\text { branching, cribriform, } \\
\text { irregular, solid }\end{array}$ & $\begin{array}{l}\text { branching, cribriform, irregular, } \\
\text { solid }\end{array}$ \\
\hline Expansion & up/down & till surface & till surface & lateral expansion \\
\hline Epithelial differentation & up/down & $\begin{array}{l}\text { top-down and exceptional } \\
\text { down-top }\end{array}$ & no maturation towards surface & \\
\hline Goblet cells & ++ & $(+)$ & $-/(+)$ retronuclear, atypic & changing \\
\hline Nuclear rows & 1 & $2-3$ & $2-5$ & vesicular \\
\hline Nuclear size & small, basal & palisading & enlarged & $++/+++$ \\
\hline Chromatin & few & + & ++ & several/ prominent \\
\hline Nucleoli & none & none & few small & \\
\hline
\end{tabular}

Modified from [3, 4, 73].

search for primary studies was limited to those published after the last search date of the most recently published systematic review, i.e. if the systematic review had searched primary studies until February 2006, primary studies published after February 2006 were sought. If no systematic reviews were found, a search for primary studies published since 2000 was performed.

In selected cases references not identified by the above process were included in the evidence base, i.e. when authors of the chapters found relevant articles published after 2008 during the period when chapter manuscripts were drafted and revised prior to publication. The criteria for relevance were: articles concerning new and emerging technologies where the research grows rapidly, high-quality and updated systematic reviews, and large trials giving high contribution to the robustness of the results or allowing upgrading of the level of evidence.

The methodological quality of the retrieved publications was assessed using the criteria obtained from published and validated check lists. Evidence tables were prepared for the selected studies. The evidence tables, clinical questions and bibliographic literature searches are documented elsewhere [33].

\section{Results}

$\nabla$

Chapter 7 in the European Guidelines [51] includes 23 recommendations on quality assurance in pathology formulated according to the level of the evidence and the strength of the recommendation. To avoid repetition, the annex describes in greater detail some of the issues raised in the chapter but it does not repeat any of the graded recommendations.

\section{A. 1 Introduction}

European Guidelines for quality assurance of pathology in colorectal cancer screening and diagnosis should provide multidisciplinary standards and best practice recommendations that can be implemented routinely across the EU. The authors therefore chose to limit the scope of the chapter on quality assurance in pathology [51] and to describe in greater detail in an annex some issues raised in the chapter, particularly details of special interest to pathologists. We also felt that an annex would be the appropriate place to point out new insights not yet widely adopted in Europe in routine practice that may be included in future updates of the Guidelines.

\section{A. 2 Grading of neoplasia}

In the present Guidelines, a classification system for colorectal neoplasia has been recommended based on a modified version of the revised Vienna classification (Section 7A.3). For readers not yet familiar with the Vienna classification, it may be helpful to note that it is the first classification to include a clinical recommendation for each neoplastic category. Furthermore, the system was developed to improve diagnostic reproducibility in the interpretation of biopsy specimens and subsequent resection specimens [54-56]. Strictly speaking, the Vienna classification is only valid for biopsy specimens, since a clinical recommendation should follow. However, to avoid diagnostic inconsistencies, the Vienna classification can be used for resection specimens as well. In the Vienna classification and hence in the European Guidelines, the term neoplasia rather than dysplasia is used to refer to epithelial tumours associated with chronic inflammatory diseases. Whereas the Vienna classification differentiates between strictly intraepithelial lesions and those involving the lamina propria, the European Guidelines only refer to mucosal neoplasia that may or may not involve the lamina propria (see Section 7A.3). More importantly, the EU Guidelines recommend a twotiered grading of mucosal neoplasia. The pathologist must decide whether a neoplastic mucosal lesion can be categorised as low or as high grade; for criteria, see $\bullet$ Table 7A.1.

As always in neoplasia, the lesion should reach the mucosal surface (no epithelial maturation). Undermining edges of an adjacent carcinoma should be excluded.

The criteria in $\odot$ Table 7A.1 can be weighted. The most important criteria for the diagnosis of carcinoma are the lateral expansion and the number of nuclear rows. In carcinoma, the number of nuclear rows should change within a single gland. High-grade neoplasia is diagnosed when the nuclear rows do not exceed $2-5 \mathrm{nu}-$ clei, and the glands do not show lateral expansion. Low-grade neoplasia is diagnosed when the nuclear rows do not exceed 2 3 nuclei $[1,2,84]$.

In histopathology, the entity of carcinoma in situ is generally defined as carcinoma confined to the epithelial layer. In squamous epithelium such an entity can be readily diagnosed. In columnar epithelium, an analogous entity should theoretically also exist. However, to date there are no exact criteria that would permit diagnosis and that would enable the histopathologist to distinguish high-grade intraepithelial neoplasia from mucosal carcinoma that is invasive in the lamina propria. Therefore, throughout the entire gastrointestinal tract, use of the term carcinoma in situ is not recommended for respective lesions in columnar epithelium. 
The term intramucosal carcinoma is widely introduced in the upper GI tract but not yet in the lower GI tract (see also Section 7A.4.5). We prefer the term mucosal neoplasia to intraepithelial neoplasia as high-grade dysplasia can contain epithelial neoplasia and invasion into the lamina propria according to the TNM classification.

\section{A. 3 Classification of serrated lesions}

\section{A. 3. 1 Terminology}

The terminology is still under discussion. Serrated lesions can be regarded as a continuous spectrum of colorectal lesions with increasingly more pronounced serrated morphology starting with a hyperplastic polyp and progressing to sessile serrated lesions (SSLs, sometimes referred to as sessile serrated adenomas or sessile serrated polyps), traditional serrated adenomas (TSA), and leading, finally, to adenocarcinoma. Not only the adenomatous component but also other alterations associated with more pronounced serrated morphology may potentially progresses to cancer (see $\bullet$ Table 7A.2).

The situation involving sessile serrated lesions is complicated as these lesions only reveal complex structural abnormalities, not adenomatous changes. Therefore, these lesions are neither adenomatous nor are they neoplastic. This is why Kudo et al. [26] and Lambert et al. [27] recommended that these lesions no longer be called adenomas; instead they should be referred to as sessile serrated lesions (SSLs). Few of these lesions are reported to rapidly progress to invasive carcinoma [48]. Those few cases that do progress rapidly, particularly in the right colon, may be expected to appear more frequently as interval cancers. Traditional serrated adenomas (TSAs), unlike SSLs, do contain adenomatous alterations, albeit sometimes quite subtle [31]; they are therefore termed correctly and treatment and surveillance should correspond to that of adenomas (see Chapters 8 and 9).

Due to the continuous spectrum in the serrated pathway to colorectal cancer, lesions with combinations of serrated morphology and adenomatous cytology can be observed. If more than one histopathologic type in the serrated spectrum (HP, SSL, TSA) is discernible in a given lesion, or at least one type in combination with adenomatous tissue, such lesions are referred to as mixed polyps. The different histopathologic types (e.g. HP and SSL, SSL and TSA, adenoma and SSL, etc.) must be stated in the diagnosis.

\section{A. 3. 2 Hyperplastic polyp}

Hyperplastic polyps (HPs) are composed of elongated crypts (no complex architecture) with serrated architecture in the upper half of the crypt. These polyps usually show some proliferation in the basal (non-serrated) part of the crypts (regular proliferation). Nuclei are small, regular, basal-orientated and lacking hyperchromasia, but with stratification of the upper (serrated) half of the crypts, and without cytological or structural signs of neoplasia.

Differences in the appearance of the cytoplasma permit recognition of three types:

- Microvesicular type (MVHP);

- Goblet-cell-rich type (GCHP); and

- Mucin-poor type (MPHP)

The microvesicular variant greatly predominates, but distinction between types is subject to wide interobserver variation, especially in small lesions, and is not always possible. Currently, routine subclassification is therefore neither feasible, nor has it been shown to be beneficial.
Table 7A.2 Continuous spectrum of serrated lesions and possible combinations of histopathologic types. Every lesion can give rise to adenocarcinoma. Most of the adenocarcinomas are believed to derive from adenomatous components.

\begin{tabular}{|lll|}
\hline Lesion & $\begin{array}{l}\text { Neopla- } \\
\text { sia }\end{array}$ & Risk of malignant transformation \\
\hline $\begin{array}{l}\text { Hyperplastic } \\
\text { polyp }\end{array}$ & no & minimal \\
$\begin{array}{l}\text { Sessile serrated } \\
\text { lesion }\end{array}$ & no & $\begin{array}{l}\text { slightly increased but exact data are } \\
\text { missing (rapid transformation may be } \\
\text { possible in a short time) }\end{array}$ \\
\hline $\begin{array}{l}\text { Traditional serra- } \\
\text { ted adenoma }\end{array}$ & yes & $\begin{array}{l}\text { increased and suggested worse } \\
\text { prognosis than carcinomas arising in } \\
\text { sessile serrated lesions }\end{array}$ \\
\hline $\begin{array}{l}\text { Mixed polyp } \\
\text { increased, but exact data are not } \\
\text { available }\end{array}$ \\
\hline $\begin{array}{l}\text { Adenoma (tubu- } \\
\text { lar, villous) }\end{array}$ & yes & increased, 17 years on average \\
\hline
\end{tabular}

At the molecular level the microvesicular variant of HP may be the precursor lesion for sessile serrated lesion, and a goblet-cellrich HP may be the precursor lesion for a traditional serrated adenoma $[40,41,66]$. Routine distinction of these types is not necessary.

\section{A. 3. 3. Sessile serrated lesion}

Sessile serrated lesions are described in the literature as "sessile serrated adenoma" and are often found in the right colon. This is a misnomer since sessile serrated lesions do not contain adenomatous changes [15,26,27].

To date, four synonymously used terms exist for these lesions: sessile serrated adenoma [67], superficial serrated adenoma [47], Type 1 serrated adenoma [19], and serrated polyp with abnormal proliferation [66].

We recommend using only the term sessile serrated lesion and avoiding use of any other terms for this entity. This recommendation is given in full awareness that sessile serrated lesions do not show histological signs of an adenoma, but, like adenomas, they should be excised if detected during an endoscopic examination. Currently even in the hands of expert GI pathologists the agreement on the sub-types of serrated lesions is only moderate [85]. The vast majority of SSLs will not progress to adenocarcinoma. Histological criteria of these sessile, usually larger lesions include an abnormal proliferation zone with structural distortion, usually most pronounced in dilatation of the crypts, particularly near the base. Abundant mucus production is usually also observed as pools of mucin in the lumen of the crypts and on the surface of the mucosa. SSLs are found mainly in the right colon and may be misdiagnosed as hyperplastic polyps. Clues to the correct diagnosis include location and large size. As discussed above, cytological signs of "neoplasia" are lacking, but structural abnormalities are present, i.e. glandular branching [15].

Sessile serrated lesions have an elevated serration index and serration in the basal half of crypts with basal dilation of crypts. The epithelium/stroma-ratio is believed to be $>50 \%$ in SSL. There is crypt branching with horizontal growth (above muscularis mucosae; e.g. T- and L-shaped glands) and often pseudoinvasion into the submucosal layer, rectangular dilation of whole crypts with and without presence of mucus, increased number of goblet cells at the base of the crypts, vesicular nuclei with prominent nucleoli and proliferation zone in the middle of the crypts. Cur- 


\begin{tabular}{|llll|}
\hline Lesion & $\begin{array}{l}\text { Number (n=414) } \\
\text { (\% of all lesions) }\end{array}$ & $\begin{array}{l}\text { Proximal location } \\
\text { (\% of BRAF mutations) }\end{array}$ & $\begin{array}{l}\text { Distal location } \\
\text { (\% of BRAF mutations) }\end{array}$ \\
\hline Hyperplastic polyp & $120(29 \%)$ & $35(29 \%)$ & $85(71 \%)$ \\
\hline Sessile serrated lesion & $36(9 \%)$ & $27(75 \%)$ & $9(25 \%)$ \\
\hline Trad. serrated adenoma & $3(1 \%)$ & $2(66 \%)$ & $1(33 \%)$ \\
\hline Mixed polyp & $7(2 \%)$ & $4(57 \%)$ & $3(43 \%)$ \\
\hline Tubular adenoma & $237(57 \%)$ & $176(74 \%)$ & $61(26 \%)$ \\
\hline Villous adenoma & $11(3 \%)$ & $6(55 \%)$ & $5(45 \%)$ \\
\hline
\end{tabular}

Table 7A.3 Prevalence of serrated lesions with BRAF Mutation: A prospective study of patients undergoing colonoscopy.

Source: modified from [63].

rently there is insufficient evidence available in the literature for weighting of these criteria.

A well-oriented polypectomy is mandatory for the identification of such histological features. Correct assessment of the deepest portions of the mucosa is impossible in superficial or tangentially cut lesions [40,41].

Further criteria include an often asymmetrical expansion of the proliferation zone into the middle third of crypts. Often mild cytological atypia (slightly enlarged vesicular nuclei, nucleoli) is found without clear signs of neoplasia (dysplasia).

BRAF-Mutations depend on the type and location of lesion (see - Table 7A.3).

Other abnormalities include:

- The majority of SSL and TSA show CIMP and promoter methylation of hMLH1

- BRAF mutations in $8-10 \%$ of all CRC (27 - $76 \%$ of CIMP and sporadic MSI-H CRC)

- BRAF mutations in the majority of SSL and TSA (also microvesicular variant of HP, especially proximal), but rarely $(0-5 \%)$ in adenoma. [13,20, 23,43-46,52,60,64,69,70].

The frequency of sessile serrated lesions in small retrospective series is estimated at $2-11 \%$ of all mucosal lesions in the colon [5,21]; between $8 \%$ and $23 \%$ are misdiagnosed as hyperplastic polyps with an interobserver variation of up to $40 \%[12,16,35$, 66].

The histological features separating HPs from SSLs constitute a continuous spectrum, and intermingled features can often be seen. This could explain the moderate interobserver concordance $(\mathrm{k}=0.47)$ and the overlapping proliferative activity, and may justify establishing semi-quantitative criteria for diagnosis (e.g. $>30 \%$ of undifferentiated cells) [9,53]. Only a few immunohistochemical markers (Ki67, Ki67 + CK20, MUC6) have been tested for differentiating HPs and SSAs, and their usefulness in colorectal screening and diagnosis remains to be validated $[49,68]$. At present, such an additional immunohistochemical analysis cannot be recommended (see $\bullet$ Table 7A.4).

In all likelihood, lesions formerly interpreted as mixed hyperplastic and adenomatous polyp are, in fact, SSLs complicated by conventional neoplasia [61]. Special care must be taken in such cases to document the respective histopathologic components in such mixed polyps. Sometimes the conventional neoplastic part shows features other than in classical adenomas. The nuclei are prominent, less palisading and smaller than in classical adenomas. It is not clear whether this type of morphology is distinct for serrated lesions and whether any clinical implications can be drawn.

Prospective studies with risk stratification are needed to develop more precise methods of diagnosis and recommendations for classification. Sessile serrated lesions appear to take a long time (average 17 years) to develop into an invasive carcinoma. In contrast, an ill-defined, small subsample of SSLs seems to rapidly progress [48,
61]. Therefore, SSLs should be completely excised, particularly if they are located on the right side of the colon $[39,41]$.

Diagnosis on a biopsy is not adequate to exclude SSL since the most severe histologic changes might only appear focally within a lesion that otherwise appears to be a hyperplastic polyp [58]. The German guidelines for colorectal cancer [57] recommend complete removal and follow-up of SSL similar to adenomas. An intensive surveillance protocol is recommended for sessile serrated lesions (surveillance colonoscopy after $3-5$ years subsequent to complete excision of non-neoplastic SSL, after one year following excision of SSL HGIEN [57].

The UK guidelines [38,80-82] recommend complete excision but classify these lesions in the same risk category as hyperplastic polyps. The existing evidence base is not definitive as to the level of risk, and follow up decisions should be made locally until more evidence is forthcoming.

\section{A. 3. 4 Traditional serrated adenoma}

Traditional serrated adenomas show neoplastic crypts with a serrated structure [79]. Compared to hyperplastic polyps, the most striking diagnostic feature of traditional serrated adenomas are the complex serrated morphology and the eosinophilic, "dysplastic" cytoplasm that still can be identified in cases with invasive adenocarcinoma. These lesions also frequently show BRAF mutations and CIMP with hMLH1 promoter methylation. Additionally, so-called intraepithelial microacini can be observed in the upper half of the mucosa (ectopic crypt formation). Often these lesions are located in the distal colon and can be found more frequently in elderly female individuals $[15,31,68]$.

\section{A. 3. 5 Mixed polyp}

A mixed polyp may contain partially hyperplastic, classical adenomatous or traditional serrated adenoma or sessile serrated lesion components. Rather than a continuous spectrum such lesions most probably represent several evolutionary lines, depending on the order of certain abnormalities in genes such as APC, BRAF and KRAS [40,41]. It has to be determined whether mixed polyps represent serrated lesions complicated by conventional neoplasia [62].

Table 7A.4 Comparison of proliferative activity in adenoma, hyperplastic polyps, sessile serrated lesion and traditional serrated adenoma.

\begin{tabular}{|llll|}
\hline Ki-67 & Adenoma & Hyperplastic polyps & $\begin{array}{l}\text { Sessile serrated } \\
\text { lesion }\end{array}$ \\
\hline upper $1 / 3$ & $68.8 \%$ & $0.1 \%$ & $1.6 \%$ \\
\hline middle $1 / 3$ & $48.7 \%$ & $9.1 \%$ & $20.3 \%$ \\
\hline lower $1 / 3$ & $29.6 \%$ & $60.3 \%$ & $64.9 \%$ \\
\hline
\end{tabular}

Source: modified from $[16,61]$ 
Table 7A.5 Measurement of tumour budding. Source: modified from [6, 14, 25, 36, 37, 71, 74].

\begin{tabular}{|c|c|c|c|c|c|c|c|c|c|}
\hline Author & Year & pT & Count & Magnif. & Object. & $\begin{array}{l}\text { Area } \\
\left(\mathrm{mm}^{2}\right)\end{array}$ & Classification & Cut-off & Notes \\
\hline Ueno & 2004 & & $\mathrm{H} \& \mathrm{E}$ & & $20 x$ & 0,785 & negative/ positive & 5 & \\
\hline Ueno & 2002 & & $H \& E$ & & $25 \times$ & 0,385 & $<10 \mid>10$ & 10 & $\begin{array}{l}\text { degree of grading } \\
\text { agreement }\end{array}$ \\
\hline Ueno & 2004 & & $\mathrm{H} \& \mathrm{E}$ & 250 & $25 x$ & 0,385 & low $(<10) /$ high $(>10)$ & 10 & \\
\hline Shinto & 2005 & & $\begin{array}{l}\text { IHC: MNF } \\
116\end{array}$ & & $20 \times$ & & $\begin{array}{l}\text { low }(<10) \text { /high }(>10) \text { moderate } \\
(10-19) \text {, severe }(>20)\end{array}$ & & $\begin{array}{l}\text { idetification of cyto- } \\
\text { plasmic fragments }\end{array}$ \\
\hline Shinto & 2006 & 3 & $\begin{array}{l}\text { IHC: MNF } \\
116\end{array}$ & & $20 \times$ & & $\begin{array}{l}\text { low }(<10) / \text { high }(>10) \text { moderate } \\
(10-19) \text {, severe }(>20)\end{array}$ & & $\begin{array}{l}\text { scoring of cytoplasmic } \\
\text { fragments called now } \\
\text { podia }\end{array}$ \\
\hline Okuyama & 2002 & $\begin{array}{l}1 \text { and } \\
2\end{array}$ & H\&E & n.a. & n.a. & n.a. & present/absent & 1 & $\begin{array}{l}\text { endoscopically } \\
\text { resected tumors were } \\
\text { excluded }\end{array}$ \\
\hline Okuyama & 2003 & 3 & H\&E & n.a. & n.a. & n.a. & present/absent & 1 & \\
\hline Okuyama & 2003 & 3 & $\mathrm{H} \& \mathrm{E}$ & n.a. & n.a. & n.a. & present/absent & 1 & \\
\hline Prall & 2005 & & $\begin{array}{l}\text { IHC: MNF } \\
116\end{array}$ & 250 & & 0,785 & low/high & 25 & $\begin{array}{l}\text { ROC metastatic pro- } \\
\text { gression; } 0 \text { - } 120 \text { buds } \\
\text { range; } 14 \text { median } 20 \text {, } \\
46 \text { mean }\end{array}$ \\
\hline Kazama & 2006 & 1 & $\begin{array}{l}\text { IHC: } \\
\text { CAM5.2 and } \\
\text { AE1/AE3 }\end{array}$ & n.a. & n.a. & n.a. & present/absent & 1 & \\
\hline Kanazawa & 2007 & & $\mathrm{H} \& \mathrm{E}$ & n.a. & n.a. & n.a. & none/mild/moderate/marked & & \\
\hline Nakamura & 2008 & & $\mathrm{H} \& \mathrm{E}$ & n.a. & n.a. & n.a. & $\begin{array}{l}\text { None } / \text { mild }=\text { low } \\
\text { moderate } / \text { marked }=\text { high }\end{array}$ & & \\
\hline Choi & 2007 & $\begin{array}{l}2 \text { or } \\
\text { more }\end{array}$ & H\&E & & $20 x$ & & $(0-3) /(4-5) /(6-10) /(11-38)$ & & \\
\hline Park & 2005 & $\begin{array}{l}2 \text { or } \\
\text { more }\end{array}$ & $\mathrm{H} \& \mathrm{E}$ & & $20 x$ & & $(0-39 /(4-5) /(6-9) /(10-38)$ & & $\begin{array}{l}\text { mean intensity: } \\
(+/ \text {-SD) } 6,6+/-5,6\end{array}$ \\
\hline Hoi & 2005 & & $\mathrm{H} \& \mathrm{E}$ & 200 & $40 x$ & & & 0,05 & $\begin{array}{l}5 \% \text { of the horizontal } \\
\text { length of the invasive } \\
\text { front }\end{array}$ \\
\hline Yasuda & 2007 & & $\mathrm{H} \& \mathrm{E}$ & & & & present/absent & & \\
\hline Ishikawa & 2008 & & IHC: MNFIIb & 400 & & & negative/ positive & 5 & \\
\hline
\end{tabular}

Focal, hyperplastic-like narrowing of the basal region of a few crypts in SSL and the findings of flat sectors or ectopic crypt formation in SSL/TSA [68] are examples of combinations of serrated and adenomatous components. However, these features add no information of further diagnostic value; they probably result from the continuous developing nature of serrated lesions. We therefore recommend that the diagnosis of mixed polyp should be restricted to the definition given in Section 7A.3.1. Mixed polyps are serrated lesions in which more than one histopathologic type in the serrated spectrum (HP, SSL, TSA) is discernible in a given lesion or at least one type in combination with classical (unserrated) adenomatous tissue. The different histopathological types must be mentioned in the diagnosis, e.g. mixed polyp (HP and SSL, adenoma and SSL).

\section{A. 3. 6 Risk of progression}

The vast majority of hyperplastic polyps and serrated lesions will not undergo malignant transformation. Only a fraction, especially in the group of sessile serrated lesions, may progress to rapidly aggressive carcinoma [5, 63].

Hyperplastic polyps rarely progress to carcinoma. A single case report can be found in the literature [78] and a second (unpublished) case has been reported in southern Germany. Interestingly, these carcinomas show features of gastric differentiation.

Little evidence is available on which the risk of colorectal cancer associated with serrated lesions other than hyperplastic polyps could be reliably judged. The risk assessment for sessile serrated lesions is not yet defined, but a subset of these lesions appears to give rise to carcinoma often less than a few millimetres in size. In a series of 110 traditional serrated adenomas, 37\% exhibited foci of significant neoplasia and $11 \%$ contained areas of intramucosal carcinoma [31]. Mixed polyps (e.g., HP/TSA/SSL or HP/adenoma) seem to have at least the same rate of progression to colorectal carcinoma as adenomas, and the risk might be higher $[17,28]$.

\section{A. 4 Assessment of T1 adenocarcinoma}

Careful assessment in T1 adenocarcinoma is mandatory because a decision is required on local excision or a major operation.

\section{A. 4. 1 Size}

Firstly, accurate measurement is very important, and measurement must be to the nearest $\mathrm{mm}$ (and not rounded-up to the nearest 5 or $10 \mathrm{~mm}$ ). The maximum size of the lesion should be measured from the histological slide and if the lesion is disrupted or too large, from the formalin-fixed macroscopic specimen. If a biopsy is received it should be stated that size cannot be assessed.

\section{A. 4. 2 Tumour grade}

Poorly differentiated carcinomas are identified by the presence of either irregularly folded, distorted and often small tubules, or the lack of any tubular formation and showing marked cytological pleomorphism. In the absence of good evidence, we recommend 
that a grade of poor differentiation should be applied in a pT1 cancer when ANY area of the lesion is considered to show poor differentiation. It should be noted that this is not in accordance with the WHO classification that recommends a certain proportion of lesion showing poor differentiation before diagnosing a lesion as G3.Poor differentiation includes undifferentiated and poorly differentiated as defined by the WHO classification [77, 79].

\section{A. 4. 3 Budding}

Budding describes the biological behaviour of the tumour at the front of invasion [8]. Budding or tumour cell dissociation [11] can be divided into slight, moderate and marked and is known from the Japanese literature of the 1950 s [18] and 1990 s [24].

At this time, evidence is lacking concerning reproducibility of the numerous methods for tumour budding measurement (see $\bullet$ Table 7A.5). It is good practice but not mandatory to document the presence or absence of single tumour cells at the front of invasion, and we therefore recommend providing this additional information in the written report with an explanatory comment, as budding has been suggested as a prognostic factor in colorectal cancer $[36,42,65]$.

\section{A. 4. 4 Site}

The site of origin of each specimen should be individually identified by the clinician and reported to the pathologist on the histopathology request form. The pathologist should record this on the proforma. This is important information because the risk of lymph node metastasis from a T1 adenocarcinoma varies depending on the site and size of the lesion (rectum vs. other locations) [50].

\section{Definition of invasion}

In columnar epithelium, it is difficult to define the onset of invasive carcinoma and reliably distinguish it from high-grade intraepithelial neoplasia. Criteria such as single tumour cells are more likely to be seen in more advanced carcinomas, but not in early carcinomas. Desmoplastic stromal reactions are also seldom seen in very early carcinomas. However, basal membrane structures are frequently discernible in well-differentiated early carcinomas $[3,4,73]$, so that definitions using "invasion through the basement membrane" are incorrect.

The WHO definition of adenocarcinoma in use when the EU Guidelines were developed excluded diagnosis of intramucosal carcinoma in the colon or rectum, in contrast to the accepted WHO definitions for the stomach, oesophagus and small bowel. In the latter cases, a decision on surgical vs. local therapy is made based on respective protocols. Comparable lesions in the colon and rectum are reported as high-grade mucosal neoplasia because a carcinoma in the colon is defined by infiltration of the submucosa according to the WHO classification.

The discussion on this issue among the authors of the pathology chapter in the EU Guidelines reflects, among other things, concern about potential overtreatment of early T1 carcinomas which are detected much more frequently in a screening setting. The clinical management of a lesion where invasion of the lamina propria has occurred is no different from that where high-grade changes are confined to the glands. This legitimate concern as to increased morbidity and mortality due to miscommunication of diagnostic criteria may be dealt with more effectively in the future, as multidisciplinary management of lesions detected in and outside of screening programmes advances. The authors hope that such advances and their effective dissemination will be stimulated by the publication of the new EU guidelines. This, in turn, may lead to revision of the current WHO definition of colorectal adenocarcinoma in a future revision of the WHO classification of gastrointestinal tumours. Pathologists should report on what version of the WHO and TNM classifications their diagnosis is based.

In those cases in which intramucosal colorectal cancer is suspected, and particularly in countries in which this diagnosis is documented in addition to the WHO terminology, explicit comments by the pathologist are recommended. Based on the cytological characteristics of the case, the pathologist should indicate whether local endoscopic or surgical removal is recommended, and the basis for this recommendation should be indicated. This recommendation should be discussed in a multidisciplinary conference prior to surgery. The Japanese criteria for such stratification have been published by Watanabe \& Suda [78]. The updated Paris classification based on a workshop in February 2008 in Kyoto [26] permits such subclassification based on improved grouping and explains in detail the grading criteria [27].

The use of the term colonic carcinoma in situ introduced by the TNM system is inadequate because the criteria are too vague and cannot be used for columnar epithelium.

A subclassification of all carcinomas into low risk and high risk based on risk of lymph node involvement should always be undertaken. For exact criteria, please see Chapter 7 and the updated Paris classification $[26,27]$.

\section{Perineural invasion}

Perineural invasion (PNI) was recently described as an independent risk factor for colorectal cancer $[29,50]$. PNI is significantly associated with high tumour stage, grade and metastases. Furthermore, PNI serves as an independent predictor of diseasefree and cancer survival $[29,50]$. Recently, an association with other criteria indicating an aggressive course of disease, such as lymphatic vessel permeation, venous invasion, tumour growth pattern and budding [22] were described by Poeschi et al. [50]. Also, it was described that PNI-positive tumours are more likely to be incompletely resected and more likely to progress after Mayo regimen chemotherapy than PNI-negative tumours. Lately Poeschl et al. were able to show that PNI is an additional independent factor for local tumour relapse.

It is recommended to record PNI in routine sections of colorectal cancer. According to recent studies $[29,30,32,50]$ immunohistochemistry or special stains are not necessary to detect PNI. Prospective studies are needed to show the clinical relevance of PNI, its relationship to other features such as lymphatic and vascular invasion and the benefit of alternative treatment for such more aggressive tumours that are PNI positive.

\section{Conclusions}

$\nabla$

Due to the unabated expansion of screening programmes in Europe in the coming years, pathologists will be dealing with an increasing number of colorectal lesions that require more specialized knowledge in order to provide the information needed by clinicians to further improve patient outcomes. In addition to other emerging topics, pathologists dealing with colorectal cancer screening should pay particular attention to continuing advances in grading of neoplasia, classification of serrated lesions and assessment of pT1 cancers. 


\section{Disclaimer}

The views expressed in this document are those of the authors. Neither the European Commission nor any person acting on its behalf can be held responsible for any use that may be made of the information in this document.

\section{Competing interests: No competing interests reported.}

\section{Institutions}

${ }^{1}$ Institute of Pathology, Klinikum Bayreuth, Bayreuth, Germany

2 Pathology and Tumour Biology, Leeds Institute of Molecular Medicine, University of Leeds, Leeds, United Kingdom

${ }^{3}$ Screening Group, Early Detection and Prevention Section, International Agency for Research on Cancer, Lyon, France

${ }^{4}$ Quality Assurance Group, Early Detection and Prevention Section, International Agency for Research on Cancer, Lyon, France

${ }^{5}$ Pathology Department, Institute for Cancer Research and Treatment, Turin, Italy

\section{Acknowledgements}

A preliminary version of the present paper, but with a slightly different format and text has been published elsewhere [72]. The comments and suggestions received from consultation of the European Cancer Network are gratefully acknowledged.

Phil Quirke is supported by Yorkshire Cancer Research and the Department of Health/Cancer Research UK Experimental Cancer Medicine Centre Initiative.

The production of the Guidelines was supported by the European Union through the EU Public Health Programme, (grant agreement no.2005317: Development of European Guidelines for Quality Assurance of Colorectal Cancer Screening). Partner institutions: Oxford University Cancer Screening Research Unit, Cancer Epidemiology Unit, University of Oxford, Oxford, United Kingdom; Unit of Cancer Epidemiology, Centre for Cancer Epidemiology and Prevention (CPO) and S.Giovanni University Hospital, Turin, Italy; Public Association for Healthy People, Budapest, Hungary; European Cancer Patient Coalition (ECPC), Utrecht, Netherlands ; Quality Assurance Group, Section of Early Detection and Prevention, International Agency for Research on Cancer, Lyon, France.

Financial support was also received through the Public Affairs Committee of the United European Gastroenterology Federation, and from a cooperative agreement between the American Cancer Society and the Division of Cancer Prevention and Control at the Centers for Disease Control and Prevention.

\section{References}

1 Ajioka Y, Watanabe H, Kazama S et al. Early colorectal cancer with special reference to the superficial nonpolypoid type from a histopathologic point of view. World J Surg 2000; 24: 1075-1080

2 Ajioka Y, Watanabe H, Kobayashi M et al. Macroscopic classification of colorectal (minute) neoplasia. I to Cho 1994; 29: 89

3 Borchard F. Forms and nomenclature of gastrointestinal epithelial expansion: what is invasion? Verh Dtsch Ges Pathol 2000; 84: 50-61

4 Borchard F, Heilmann KL, Hermanek $P$ et al. Definition and clinical significance of dysplasia in the digestive tract. Results of a meeting of the Society of Gastroenterologic Pathology of the German Society of Pathology 25 November 1989 in Kronberg. Pathologe 1991; 12: 50 - 56

5 Carr NJ, Mahajan H, Tan KL et al. Serrated and non-serrated polyps of the colorectum: their prevalence in an unselected case series and correlation of BRAF mutation analysis with the diagnosis of sessile serrated adenoma. J Clin Pathol 2009; 62: 516-518

6 Cooper HS, Deppisch LM, Gourley WK et al. Endoscopically removed malignant colorectal polyps: clinicopathologic correlations. Gastroenterology 1995; 108: 1657-1665
7 Council of the European Union. Council Recommendation of 2 December 2003 on cancer screening (2003/878/EC). Off J Eur Union; 2003: $34-38$

8 Deinlein $P$, Reulbach $U$, Stolte $M$ et al. Risk factors for lymphatic metastasis from pT1 colorectal adenocarcinoma. Pathologe 2003; 24: 387 393

9 Farris AB, Misdraji J, Srivastava A et al. Sessile serrated adenoma: challenging discrimination from other serrated colonic polyps. Am J Surg Pathol 2008; 32: $30-35$

10 Ferlay J, Shin HR, Bray F et al. GLOBOCAN 2008 v1.2, Cancer Incidence and Mortality Worldwide: IARC CancerBase No. 10. [Internet] Lyon, France: International Agency for Research on Cancer; 2010: Available from: http://globocan.iarc.fr Accessed on 05/04/2012

11 Gabbert HE, Meier S, Gerharz CD et al. Tumor-cell dissociation at the invasion front: a new prognostic parameter in gastric cancer patients. Int J Cancer 1992; 50: 202 - 207

12 Goldstein NS, Bhanot P, Odish E et al. Hyperplastic-like colon polyps that preceded microsatellite-unstable adenocarcinomas. Am J Clin Pathol 2003; 119: 778 - 796

13 Grady WM, Carethers JM. Genomic and epigenetic instability in colorectal cancer pathogenesis. Gastroenterology 2008; 135: 1079-1099

14 Haggitt RC, Glotzbach RE, Soffer EE et al. Prognostic factors in colorectal carcinomas arising in adenomas: implications for lesions removed by endoscopic polypectomy. Gastroenterology 1985; 89: 328 - 336

15 Higuchi T, Jass JR. My approach to serrated polyps of the colorectum. J Clin Pathol 2004; 57: 682-686

16 Higuchi T, Sugihara K, Jass JR. Demographic and pathological characteristics of serrated polyps of colorectum. Histopathology 2005; 47: 32 40

17 Hyman $\mathrm{NH}$, Anderson P, Blasyk $H$. Hyperplastic polyposis and the risk of colorectal cancer. Dis Colon Rectum 2004; 47: 2101 - 2104

18 Imai T. The growth of human carcinoma: a morphological analysis. Fukuoka Igaku Zasshi 1954; 45: 13-43

19 Jaramillo E, Tamura S, Mitomi $H$. Endoscopic appearance of serrated adenomas in the colon. Endoscopy 2005; 37: 254-260

20 Jass JR. Classification of colorectal cancer based on correlation of clinical, morphological and molecular features. Histopathology 2007; 50: $113-130$

21 Jass JR, Baker K, Zlobec I et al. Advanced colorectal polyps with the molecular and morphological features of serrated polyps and adenomas: concept of a "fusion" pathway to colorectal cancer. Histopathology 2006; 49: $121-131$

22 Jass JR, Love SB, Northover JM. A new prognostic classification of rectal cancer. Lancet 1987; 1: 1303-1306

23 Kawasaki T, Ohnishi M, Nosho K et al. CpG island methylator phenotype-low (CIMP-low) colorectal cancer shows not only few methylated CIMP-high-specific CpG islands, but also low-level methylation at individual loci. Mod Pathol 2008; 21: 245 - 255

24 Kobayashi M, Watanabe H, Maeo S et al. Correlation of histological atypia and cancer-sprouting with vascular permeation and lymph nodal metastasis by our new histological classification of submucosal invasion by colorectal carcinomas. Stomach Intest 1994; 29: $1151-1156$

25 Konishi F, Morson BC. Pathology of colorectal adenomas: a colonoscopic survey. J Clin Pathol 1982; 35: 830-841

26 Kudo S, Lambert R, Allen JI et al. Nonpolypoid neoplastic lesions of the colorectal mucosa. Gastrointest Endosc 2008; 68: 3-47

27 Lambert R, O'Brien MJ, Jaramillo E et al. The serrated pathway to colorectal cancer. World Gastroenterology News 2009; 14: 5-10

28 Leggett BA, Devereaux B, Biden K et al. Hyperplastic polyposis: association with colorectal cancer. Am J Surg Pathol 2001; 25: 177-184

29 Liebig C, Ayala G, Wilks J et al. Perineural invasion is an independent predictor of outcome in colorectal cancer. J Clin Oncol 2009; 27: $5131-5137$

30 Liebig C, Ayala G, Wilks JA et al. Perineural invasion in cancer: a review of the literature. Cancer 2009; 115: $3379-3391$

31 Longacre TA, Fenoglio-Preiser CM. Mixed hyperplastic adenomatous polyps/serrated adenomas. A distinct form of colorectal neoplasia.. Am J Surg Pathol 1990; 14: 524-537

32 Marshall CL, Liebig C, Wilks J et al. Reply to E.M. Poeschl et al. J Clin.Oncol 2010

33 Minozzi S, Armaroli P, Banzi R et al. European guidelines for quality assurance in colorectal cancer screening and diagnosis - First edition. Appendix 1: Systematic evidence review. 2010: http://bookshop.europa.eu/en/european-guidelines-for-quality-assurance-in-colorectalcancer-screening-and-diagnosis-pbND3210390/ Accessed 11/2/2012 
34 Minozzi S, Armaroli P, Segnan N. European guidelines for quality assurance in colorectal cancer screening and diagnosis. First edition. Principles of evidence assessment and methods for reaching recommendations. Endoscopy 2012; 44: SE9-SE14

35 Montgomery E. Serrated colorectal polyps: emerging evidence suggests the need for a reappraisal. Adv Anat Pathol 2004; 11: $143-149$

36 Nakamura T, Mitomi H, Kanazawa $\mathrm{H}$ et al. Tumor budding as an index to identify high-risk patients with stage II colon cancer. Dis Colon Rectum 2008; 51: $568-572$

37 Nascimbeni R, Burgart LJ, Nivatvongs $S$ et al. Risk of lymph node metastasis in T1 carcinoma of the colon and rectum. Dis Colon Rectum 2002; 45: $200-206$

38 NHS Bowel Cancer Screening Programme. Reporting lesions in the NHS Bowel Cancer Screening Programme - guidelines from the Bowel Cancer Screening Programme Pathology Group. 2007: http://www. cancerscreening.nhs.uk/bowel/publications/nhsbcsp01.pdf Accessed $11 / 2 / 2012$

39 Noffsinger AE. Serrated polyps and colorectal cancer: new pathway to malignancy. Annu Rev Pathol 2009; 4: 343-364

40 O'Brien MJ. Hyperplastic and serrated polyps of the colorectum. Gastroenterol Clin North Am 2007; 36: 947 - 68 viii

41 O'Brien MJ, Yang S, Huang CS et al. The serrated polyp pathway to colorectal carcinoma. Diagnostic Histopathology 2008; 14: 78 -93

42 Ogawa T, Yoshida T, Tsuruta T et al. Tumor budding is predictive of lymphatic involvement and lymph node metastases in submucosal invasive colorectal adenocarcinomas and in non-polypoid compared with polypoid growths. Scand J Gastroenterol 2009; 44: 605-614

43 Ogino S, Goel A. Molecular classification and correlates in colorectal cancer. J Mol Diagn 2008; 10: 13-27

44 Ogino S, Kawasaki T, Kirkner GJ et al. Evaluation of markers for CpG island methylator phenotype (CIMP) in colorectal cancer by a large population-based sample. J Mol Diagn 2007; 9: 305-314

45 Ogino S, Kawasaki T, Kirkner GJ et al. CpG island methylator phenotype-low (CIMP-low) in colorectal cancer: possible associations with male sex and KRAS mutations. J Mol Diagn 2006; 8: 582 - 588

46 Ogino S, Nosho K, Kirkner GJ et al. CpG island methylator phenotype, microsatellite instability, BRAF mutation and clinical outcome in colon cancer. Gut 2009; 58: $90-96$

47 Oka S, Tanaka S, Hiyama T et al. Clinicopathologic and endoscopic features of colorectal serrated adenoma: differences between polypoid and superficial types. Gastrointest Endosc 2004; 59: 213 -219

48 Oono Y, Fu K, Nakamura $\mathrm{H}$ et al. Progression of a sessile serrated adenoma to an early invasive cancer within 8 months. Dig Dis Sci 2009; 54 : 906-909

49 Owens SR, Chiosea SI, Kuan SF. Selective expression of gastric mucin MUC6 in colonic sessile serrated adenoma but not in hyperplastic polyp aids in morphological diagnosis of serrated polyps. Mod Pathol 2008; 21: $660-669$

50 Poeschl EM, Pollheimer MJ, Kornprat P et al. Perineural Invasion: Correlation With Aggressive Phenotype and Independent Prognostic Variable in Both Colon and Rectum Cancer. J Clin Oncol 2010

51 Quirke P, Risio M, Lambert R et al. European guidelines for quality assurance in colorectal cancer screening and diagnosis: Chapter 7 - Quality assurance in pathology in colorectal cancer screening and diagnosis. Endoscopy 2012; 44: SE116-SE130

52 Samowitz WS, Slattery ML, Sweeney $C$ et al. APC mutations and other genetic and epigenetic changes in colon cancer. Mol Cancer Res 2007; 5: $165-170$

53 Sandmeier D, Seelentag $W$, Bouzourene H. Serrated polyps of the colorectum: is sessile serrated adenoma distinguishable from hyperplastic polyp in a daily practice? Virchows Arch 2007; 450: 613-618

54 Schlemper RJ, Kato Y, Stolte M. Diagnostic criteria for gastrointestinal carcinomas in Japan and Western countries: proposal for a new classification system of gastrointestinal epithelial neoplasia. J Gastroenterol Hepatol 2000; 15: 49-G57

55 Schlemper RJ, Kato Y, Stolte M. Review of histological classifications of gastrointestinal epithelial neoplasia: differences in diagnosis of early carcinomas between Japanese and Western pathologists. J Gastroenterol 2001; 36: $445-456$

56 Schlemper RJ, Riddell RH, Kato Y et al. The Vienna classification of gastrointestinal epithelial neoplasia. Gut 2000; 47: 251 - 255

57 Schmiegel W, Reinacher-Schick A, Arnold D et al. Update S3-guideline “colorectal cancer" 2008. Z Gastroenterol 2008; 46: 799-840
58 Schreiner MA, Weiss DG, Lieberman DA. Proximal and large hyperplastic and nondysplastic serrated polyps detected by colonoscopy are associated with neoplasia. Gastroenterology 2010; 139: 1497-1502

59 Segnan N, Patnick J, von Karsa L (eds.) European guidelines for quality assurance in colorectal cancer screening and diagnosis - First edition. Luxembourg: European Commission, Publications Office of the European Union; 2010

60 Shen $L$, Toyota M, Kondo Yet al. Integrated genetic and epigenetic analysis identifies three different subclasses of colon cancer. Proc Natl Acad Sci U S A 2007; 104: 18654-18659

61 Sheridan TB, Fenton H, Lewin MR et al. Sessile serrated adenomas with low- and high-grade dysplasia and early carcinomas: an immunohistochemical study of serrated lesions "caught in the act". Am J Clin Pathol 2006; 126: $564-571$

62 Snover DC, Jass JR, Fenoglio-Preiser C et al. Serrated polyps of the large intestine: a morphologic and molecular review of an evolving concept. Am J Clin Pathol 2005; 124: 380 - 391

63 Spring KJ, Zhao ZZ, Karamatic R et al. High prevalence of sessile serrated adenomas with BRAF mutations: a prospective study of patients undergoing colonoscopy. Gastroenterology 2006; 131: 1400-1407

64 Suehiro Y, Wong CW, Chirieac LR et al. Epigenetic-genetic interactions in the APC/WNT, RAS/RAF, and P53 pathways in colorectal carcinoma. Clin Cancer Res 2008; 14: 2560 - 2569

65 Sy J, Fung CL, Dent OF et al. Tumor budding and survival after potentially curative resection of node-positive colon cancer. Dis Colon Rectum 2010; 53: $301-307$

66 Torlakovic E, Skovlund E, Snover DC et al. Morphologic reappraisal of serrated colorectal polyps. Am J Surg Pathol 2003; 27: 65 -81

67 Torlakovic E, Snover DC. Serrated adenomatous polyposis in humans. Gastroenterology 1996; 110: 748 - 755

68 Torlakovic EE, Gomez JD, Driman DK et al. Sessile serrated adenoma (SSA) vs. traditional serrated adenoma (TSA). Am J Surg Pathol 2008; 32: $21-29$

69 Toyota M, Ahuja N, Ohe-Toyota M et al. CpG island methylator phenotype in colorectal cancer. Proc Natl Acad Sci U S A 1999; 96: 8681 8686

70 Toyota M, Ohe-Toyota M, Ahuja N et al. Distinct genetic profiles in colorectal tumors with or without the $\mathrm{CpG}$ island methylator phenotype. Proc Natl Acad Sci U S A 2000; 97: 710-715

71 Ueno $H$, Mochizuki $H$, Hashiguchi Y et al. Risk factors for an adverse outcome in early invasive colorectal carcinoma. Gastroenterology 2004; 127: 385 - 394

72 Vieth M, Quirke P, Lambert R et al. Annex to Quirke et al. Quality assurance in pathology in colorectal cancer screening and diagnosis: annotations of colorectal lesions. Virchows Arch 2011; 458: 21 - 30

73 Vieth $M$, Stolte $M$. Distinction of high-grade intraepithelial neoplasia and tubular gastric adenocarcinoma. In: Kaminishi M, Takubo K, Mafune $\mathrm{K}$ (eds.) The diversity of gastric carcinoma: pathogenesis, diagnosis and therapy. Tokyo: Springer; 2005: 109-116

74 Volk EE, Goldblum JR, Petras RE et al. Management and outcome of patients with invasive carcinoma arising in colorectal polyps. Gastroenterology 1995; 109: $1801-1807$

75 von Karsa L, Anttila A, Ronco G et al. Cancer Screening in the European Union. Report on the implementation of the Council Recommendation on Cancer Screening - First Report. Luxembourg: European Commission; 2008: http://ec.europa.eu/health/archive/ph_determinants/genetics/documents/cancer_screening.pdf Accessed 11/2/2012

76 von Karsa L, Lignini TA, Patnick J et al. The dimensions of the CRC problem. Best Pract Res Clin Gastroenterol 2010; 24: 381 - 396

77 Washington MK, Berlin J, Branton P et al. Protocol for the examination of specimens from patients with primary carcinoma of the colon and rectum. Arch Pathol Lab Med 2009; 133: 1539-1551

78 Watanabe $H$, Suda T. Precancerous lesions of the colon and rectum. Gan To Kagaku Ryoho 1984; 11: 1 -9

79 WHO. Pathology and genetics of tumours in the digestive system. Carcinoma of the colon and rectum. In: Hamilton SR, Aaltonen LA (eds.) World Health Organization International Histological Classification of Tumours. Lyon: IARC Press; 2000: 105-119

80 Williams GT, Quirke P, Shepherd NA. Dataset for colorectal cancer. 2007; 2nd: edition http://www.rcpath.org/resources/pdf/G049-ColorectalDataset-Sep07.pdf Accessed 11/2/2012

81 Williams GT, Quirke P, Shepherd NA. Dataset for colorectal cancer - Appendix C: Proforma for colorectal cancer resections. 2007; 2nd: edition http://www.rcpath.org/resources/worddocs/G049ColorectalDatasetAppendixC-Sep07.doc Accessed 11/2/2012 
82 Williams GT, Quirke P, Shepherd NA. Dataset for colorectal cancer - Appendix D: Proforma for local excision specimens. 2007; 2nd: edition http://www.rcpath.org/resources/worddocs/G049ColorectalDatasetAppendixD-Sep07.doc Accessed 11/2/2012

83 Wilson JM, Jungner YG. Principles and practice of mass screening for disease. World Health Organization; 1968: http://whqlibdoc.who.int/ php/WHO_PHP_34.pdf Accessed 11/2/2012
84 Wolber RA, Owen DA. Flat adenomas of the colon. Hum Pathol 1991; 22: $70-74$

85 Wong NA, Hunt LP, Novelli MR et al. Observer agreement in the diagnosis of serrated polyps of the large bowel. Histopathology 2009; 55: $63-$ 66 